\section{Amyand's Hernia - A Rare Intraoperative Finding in Inguinal Hernias}

Sir,

Hernias are commonly encountered surgical cases worldwide. In Pakistan, most common type of hernia is inguinal hernia, which is a protrusion of an organ or fascia through the wall of its containing cavity with a prevalence of $27 \%$ in males and only $3 \%$ in females. ${ }^{1}$ Inguinal sac containing vermiform appendix; normal, inflamed or perforated, constitutes Amyand's hernia, which is extremely rare. ${ }^{2}$

Amyands's hernia has been reported from neonatal period to 92 years, ${ }^{3}$ with an incidence of $0.19 \%$ to $1.7 \%, 2,4,5$ which has been named after Claudius Amyand, who performed appendectomy in 1735 during exploration of inguinal sac, where he found a perforated appendix and fecal fistula in a 11-year boy. Appendicitis is rarer in this type of hernia with an incidence of $0.13 \%$ to $0.17 \%$ with mortality of $15 \%$ to $30 \%$ due to severe abdominal sepsis. ${ }^{5}$

We present a case of a 50-year male who presented to Outpatient Surgical Clinic at Abbasi Shaheed Hospital, for right-sided inguinoscrotal swelling, which was progressively increasing for 2 years. On examination, a swelling of approximately $10 \times 15 \mathrm{~cm}$ was noticed in the right inguinoscrotal region, which was self-reducible initially, but later he has to reduce it manually. This patient was planned to have mesh repair for which all baseline investigations were advised.

After few days, the patient presented to Emergency Department with severe pain in the swelling for 6 hours, which was localised to the swelling of the right inguinal region, associated with fever, nausea and vomiting. Physical examination of the swelling revealed erythema, tenderness, irreducibility, and audible gut sounds, for which impression of obstructed inguinal hernia was made.

Emergency surgery was done and on exploration of sac, 20-30 cc serous fluid was aspirated. Sac contained part of cecum, terminal ileum, and appendix, which was inflamed and edematous. Appendectomy was performed and all the remaining contents were reduced in to the peritoneal cavity. Classical Bassani Repair was done without any complication and surgical site was closed in layers. Patient was kept nil by mouth for 8 hours and recovery was smooth. He was discharged on $3^{\text {rd }}$ postoperative day. Follow-up was satisfactory.

Amyand's hernia prevalence and reporting in Pakistan is uncommon. It clinically presents usually as incarcerated hernia and preoperative diagnosis is nearly impossible. ${ }^{3}$ However; ultrasound and axial computed tomography with sagittal and coronal views can make the diagnoses easy. ${ }^{4}$ In our patient, it was diagnosed intraoperatively and appendectomy was performed.

\section{CONFLICT OF INTEREST:}

Authors declared no conflict of interest.

\section{AUTHORS' CONTRIBUTION:}

WK: Literature review, case reporting and writing HHA: Literature review, case reporting and writing, assistant to surgeon

MJ: Proofreading and approval of case, operating surgeon.

\section{REFERENCES}

1. Agrawal SN. A study of the demography, clinical features and management of inguinal hernia in a tertiary care hospital. J Surgery 2018; 6:5.

2. Sagar A, Sureka J. Appendix in inguinal hernia-Amyand's hernia. Indian J Surg 2013; 77(Suppl 2):733-4.

3. Ivashchuk Galyna. Amyand's hernia: A review. Med Sci Monit 2014; 20:140-6.

4. Michalinos A, Moris D, Vernadakis S. Amyand's hernia: A review. Am J Surg 2014; 207:989-95.

5. Samani RS. Amyand's hernia: An extremely rare condition of inguinal hernia accompanied with acute appendicitis. Ann Colorectal Res 2014; 2:e17748.

Wajeeha Khalid, Hajrah Hilal Ahmed and Muhammad Jamaluddin

Surgical Unit II, Abbasi Shaheed Hospital, Karachi, Pakistan

Correspondence to: Dr. Hajrah Hilal Ahmed, Surgical Unit II, Abbasi Shaheed Hospital, Karachi, Pakistan

E-mail: hajrahilal@gmail.com

Received: February 12, 2019; Revised: May 10, 2019; Accepted: May 10, 2019 